\title{
MOVILIZACIÓN Y DESMOVILIZACIÓN DEL MOVIMIENTO OBRERO EN LA TRANSICIÓN CHILENA A LA DEMOCRACIA
}

\author{
Rafael Durán Muñoz*
}

El objeto empírico de este trabajo es la transición chilena desde la dictadura de Augusto Pinochet. Más concretamente, aspiro a desvelar la importancia que el nivel y la naturaleza de las movilizaciones sociales de presión y/o protesta tuvieron en la determinación tanto del acaecimiento como del carácter de tal cambio de régimen. Desde la crítica, el artículo se pretende complementario del modelo explicativo de los transitólogos de la contingencia.

\section{REVISIÓN Y CRÍTICA DE LA LITERATURA SOBRE TRANSICIONES}

Desde los años setenta se vienen realizando análisis de las transiciones a la democracia parlamentaria desde regímenes autoritarios acaecidas tanto en América Latina como en Europa del Sur y del Este. Destaca como un cuerpo de investigación claramente definido el elaborado por los científicos sociales elitistas o de la contingencia. Atienden a las élites políticas que protagonizan tales cambios de régimen en tanto que precondición para y factor causal sobresaliente del establecimiento de una democracia consolidada. Empeñados en demostrar la bonanza de las transiciones vía transacciones, se centran de forma normativa en la habilidad, valores, estrategias y actitudes de estos actores - a los que presuponen y desean democráticamente comprometidos, flexibles, tolerantes- como factores que explican los acuerdos o "pactos fundacionales" (Karl y Schmitter, 1991) a que llegan, pueden llegar o han de llegar, y que permiten la consolidación de y, por lo tanto, la exitosa transición a la democracia (v.gr., Prewitt y Stone, 1973; Putnam, 1976; Field y Higley, 1980; O’Donnell y Schmitter, 1986; Sartori, 1987; Diamond y Linz, 1989; Przeworski, 1991; Higley y Gunther, 1992) '.

Ello no ha impedido que se tomara conciencia de las presiones ejercidas contra los regímenes dictatoriales desde la sociedad en su conjunto, desde la resurgida sociedad civil (O’Donnell y Schmitter, 1986), y desde algunos sectores en particular, el más importante de los cuales es o suele ser la clase trabajadora. Se afirma que la expresión de su descon- tento vía movilizaciones en la fase de liberalización impone a los soft-liners la disyuntiva democratización o represión; esta última, defendida por los hard-liners. Su postura será favorable a una u otra alternativa mayormente en función del control que crean tener sobre las fuerzas sociales opositoras, en gran medida determinado por sus relaciones con los moderados, $y$ de éstos con los radicales o maximalistas de la oposición al régimen; en otros términos: determinado en función de los costes de la tolerancia y de la represión ${ }^{2}$.

Con ser útil, esta aproximación a las relaciones entre el movimiento obrero, entre los distintos movimientos sociales o de masas y los procesos y fases transicionales no deja de ser excesivamente general y, en consecuencia, superficial. El análisis post facto de los desarrollos conduce a minusvaloraciones, y éstas a elusiones. Las simplificaciones en que se incurre distorsionan la compleja realidad, quizás debido a la mayor preocupación de tales autores por el cómo del establecimiento de una democracia consolidada y duradera (de ser posible, vía pacto) que por el porqué de su instauración o reinstauración. En un nivel de análisis más concreto pueden hacerse al menos tres grandes observaciones:

En primer lugar, la afirmación de que las liberalizaciones desatan la resurrección de la sociedad civil en forma de

* Universidad de Málaga.

1. "[U]nless the armed forces collapse, successful transition can be brought about only as a result of negotiations, of pacts. The political implication was that pro-democratic forces must be prudent; they must be prepared to offer concessions in exchange for democracy" (Przeworski, 1991, 98; énfasis añadido). Y concluye el autor afirmando: pese a que "the democracy that results from the ruptura pactada is inevitably conservative economically and socially, (...) anything is better than the mass murder and torture" (idem). En la misma línea, O'Donnell y Schmitter reconocen que su proyecto "tuvo desde el principio una tendencia normativa, acompañada y reforzada por una generalización empírica. Hemos reconocido [continúan] que la democracia política es deseable per se, incluso después de haber reconocido las concesiones significativas que su establecimiento y eventual consolidación pueden involucrar en los términos de oportunidades más efectivas y rápidas para reducir las desigualdades sociales y económicas" $(1986,25)$.

2. Para una definición conceptual de los dos grupos intra y extramuros, así como para una más argumentada aproximación a lo aquí sintetizado, véanse O’Donnell y Schmitter (1986) y Przeworski (1991, cap. 2). 
organizaciones y movilizaciones o acciones colectivas "almost overnight" (Przeworski, 1991, 58), "almost immediately" (O’Donnell et al., 1986, 7), niega (cuando menos, elude) la posibilidad de que éstas sean previas al, y causa del, acaecimiento de aquellas. En este sentido, Schmitter sostiene que "calculations and conflicts within the dominant group and among its privileged supporters/beneficiaries provide the major motivation for beginning a regime transformation" (idem). Tal aseveración no va acompañada de la respuesta a la pregunta que de ella misma se deriva: ¿por qué la coalición dominante -o fracciones de ellaproceden a la aplicación de reformas políticas que, intencionadamente o no, pudieren desembocar en transiciones a la democracia? En otros términos, ¿las causas que motivan esas "calculations and conflicts" son asimismo internas, propias y exclusivas del "dominant group", o por el contrario son también externas?

En segundo lugar, cuando los teóricos de la contingencia hablan del movimiento obrero hacen referencia a él, erróneamente, como algo monolítico en sus actitudes, comportamientos y objetivos, sin distinción de niveles de participación ni referencia a alineamientos político-partidistas. Se trataría, de acuerdo al modelo imperante que aquí se revisa y critica, de un actor social que, habiendo jugado algún papel en el proceso de la transición (generador de desorden e inestabilidad en la fase de liberalización), debe ser acallado en sus reivindicaciones y acciones, desmovilizado, a fin de hacer factible el pacto, la democratización y la consolidación. Se omite, por tanto, cuando menos analíticamente, la relación entre los dirigentes políticos que pactan y los movimientos y organizaciones de masas, así como entre ambas y la sociedad en su conjunto. Tales relaciones, pienso, pueden facilitar/forzar cambios estratégicos tan determinantes en el proceso de transición como la movilización/desmovilización.

Así pues, y aun siendo importante e incuestionable la aportación que ha significado este enfoque microsociológico que predomina, contiene lagunas; entre ellas, las señaladas. Debe tenerse también en cuenta, en tercer lugar, que tales análisis fueron y son una reacción en la comunidad científica contra el funcionalismo imperante desde los años cincuenta hasta principios de los setenta. De ahí que en el análisis de los procesos (re)democratizadores —en general y desde que Dankwart A. Rustow formulara su teoría genética (1970) — se hayan obviado las condiciones objetivas, salvo el tipo de régimen (vide Linz y Stepan, 1990, y Linz, 1992; cfr. Tarrow, 1995). Sin embargo, tales condiciones, estructurales, no deben necesariamente entenderse (yo no lo hago) como la existencia o no de "precondiciones" para la democracia (Lipset, 1969). Terry L. Karl y Philippe C. Schmitter (1991) advierten del peligro que el énfasis en la "contingencia" tiene de caer en el "voluntarismo excesivo" al obviar, entre otros factores, tanto las estructuras sociales y económicas y la forma de inserción en la economía internacional como las instituciones políticas existentes -o que existen en la memoria de los pueblos-; confining conditions que, interrelacionadas, restringen o fortalecen, condicionan los comportamientos y estrategias de los actores.
No debe inferirse de tales observaciones que desestimo ni aun minimizo la relevancia de las élites políticas y los acuerdos a que llegaron y llegan en los procesos de transición. En este sentido, no creo que deba ni pueda detectarse sesgo antielitista alguno en este trabajo. Por el contrario, a lo que aspiro es a enriquecer la comprensión de tales fenómenos de cambio en general y de pacto en particular intentando aportar algunas respuestas a las preguntas formuladas más arriba. En consecuencia, el planteamiento que me guía no significa sino una comprensión amplia, y no meramente elitista, de los agentes o actores intervinientes ${ }^{3}$.

Antes de seguir adelante se hace obligado definir el concepto transición. Por tal entiendo lo que O'Donnell y Schmitter definieran, con el propósito de crear "a common language for inquiry among scholars" $(1986,6)$, como

“(..) the interval between one political regime and another. (...) Transitions are delimited, on the one side, by the launching of the process of dissolution of ar. authoritarian regime and, on the other, by the installation of some form of democracy, the return to some form of authoritarian rule, or the emergence of a revolutionary alternative. It is characteristic of the transition that during it the rules of the political game are not defined" (idem).

Dos procesos pueden distinguirse en el desarrollo de las transiciones definidas: "liberalización” y "democratización”. Siguiendo a O'Donnell y Schmitter, me refiero a la fase de liberalización como aquella que inicia la transición. No tiene lugar sólo porque a raíz de la crisis del régimen (cualquiera que sea su índole) se hagan legalmente efectivos ciertos derechos que protejan tanto a individuos como a grupos sociales de la arbitrariedad estatal, gubernamental o de terceros. Para que sea así conceptualizada, la liberalización debe ser practicada por el régimen pre-existente; pero también debe ser lo suficientemente creíble para la sociedad en general y para la oposición en particular como para provocar un cambio en sus estrategias y acciones, así como debe conllevar las "unintended consequences" que finalmente obligan a la democratización, que es de hecho la mayor «"unintended" consequence».

"Democratization (...) refers to the processes whereby the rules and procedures of citizenship are either applied to political institutions previously governed by other principles (e.g., coercive control, social tradition, expert judgment, or administrative practi-

3. Pienso que toda aproximación a coyunturas y acontecimientos históricos como los referidos merece ser tratada a la luz de los argumentos teóricos de la literatura sobre acción colectiva, muy particularmente los del enfoque del proceso político (vide Tarrow, 1994). Así lo han hecho el propio Sidney Tarrow en un análisis comparado de España e Italia (1995) y Patricia L. Hipsher sobre la misma experiencia chilena y de nuevo el caso español (1996). Yo mismo lo desarrollo en mi tesis doctoral (vide Durán Muñoz, 1997). Ello no obstante, he querido limitar el presente estudio a la crítica constructiva de los argumentos de los transitólogos de la contingencia. 
ce), or expanded to include persons not previously enjoying such rights and obligations (e.g., nontaxpayers, illiterates, women, youth, ethnic minorities, foreign residents), or extended to cover issues and institutions not previously subject to citizen participation (e.g., state agencies, military establishments, partisan organizations, interest associations, productive enterprises, educational institutions, etc.)" (O’Donnell y Schmitter, 1986, 8).

Mi caso de estudio será el movimiento obrero chileno y su papel como posible actor causa en la finalización de la dictadura de Pinochet según el argumento desarrollado hasta ahora. No pienso que la transición a la democracia competitiva en Chile pueda analizarse, ni exclusiva ni principalmente, como "el resultado de dos acuerdos entre élites [elite settlements] parcial pero esencialmente simultáneos" (Cavarozzi, 1992, 224; énfasis añadido), que a su vez se explicarían por la "propensión hacia el compromiso que empezó en los treinta y como consecuencia del callejón sin salida en que políticamente se encontró el régimen autoritario a finales de los ochenta" (idem, 209). Entiendo que uno de los factores que ayudan a comprender por qué, cómo y cuándo tuvo lugar la transición es el movimiento obrero en tanto que actor social colectivo que presionara, amenazara y/o desestabilizara (o no) desde abajo.

En ninguna de las investigaciones que he consultado se hace referencia alguna a la importancia del movimiento obrero ni en la llegada ni en la clase de democracia a la que se llega en Chile a partir de 1988. Discrepo de tal omisión analítica. Tiendo a pensar, a modo de hipótesis, 1) que la politización y la movilización de los trabajadores chilenos durante la primera mitad de los ochenta transformaron el proceso de institucionalización de la dictadura abierto a finales de los setenta en uno de liberalización y 2) que tanto su desmovilización como el papel nada desafiante contra el régimen desde 1986/1987, y sobre todo en el tiempo del referéndum y de las elecciones presidenciales, permitieron, es decir, no impidieron ni dificultaron, la muy controlada democratización que estaba teniendo lugar. No trataré esta segunda fase de la transición (vide Rojas Hernández, 1993).

Al desarrollar mi argumento no me centraré en el movimiento obrero como un agente social aislado, sino en tanto que actor colectivo cuyas características se explican en función del tipo de régimen político en el que actúa (y en el que actúan muy especialmente cada uno de los individuos susceptibles de conformarlo), del sistema económico que funciona en cada periodo y en función de sus relaciones recíprocas con los partidos políticos. Si bien hay otros factores susceptibles de haber condicionado la repercusión del movimiento obrero en el cuándo, porqué y cómo de la transición, caso del contexto internacional y de instituciones nacionales como la Iglesia Católica, limitaré mi atención a los elementos referidos más arriba, y ello tanto por razones de espacio como de índole analítica.

\section{ALGUNOS ANTECEDENTES HISTÓRICOS}

Una intervención militar puso fin en 1924 a uno de los ejemplos más exitosos de democracia limitada (la participación política estaba ampliándose a nuevos sectores sociales) en la América Latina de entonces, y dio paso a la dictadura del Coronel Carlos Ibáñez. La vuelta de Alessandri en $1932^{4}$ y especialmente la victoria del Frente Popular en las elecciones de 1938 significaron el retorno gradual a la democracia liberal, además de la paralela consolidación de un sistema de partidos semejante a los europeos ${ }^{5}$. Este periodo político se extendió hasta el derrocamiento del presidente socialista Salvador Allende Gossens en 1973. Su duración fue otro factor que distinguió la democracia chilena del resto de las latinoamericanas. Una prueba de tal distinción es la referencia que hizo a ella O'Donnell cuando escribía su libro, en 1971, como caso no susceptible de autoritarismo-burocrático $(19 \mathrm{~g} 6,268)$.

El proceso de democratización sustantiva ${ }^{6}$ fue paralelo a uno de creciente intervencionismo estatal en las esferas social y económica. El desarrollo capitalista estatal chileno destacó de entre los demás países latinoamericanos desde los treinta; las autoridades gubernamentales combinaron simultáneamente políticas de sustitución de importaciones a fin de fomentar la industrialización nacional y programas de bienestar dirigidas principalmente a los trabajadores organizados. En los sesenta se practicaron políticas macroeconómicas ortodoxas (Kaufman y Stallings, 1991, 16), pero adicionalmente: al mismo tiempo, al presidente cristiano-demócrata Eduardo Frei (1964-1970) ${ }^{7}$ se debieron la "chileanización" de la industria del carbón y una ley de reforma agraria, así como impulsó la creación de sindicatos y la afiliación de nuevos miembros. Posteriormente, el gobierno de Unidad Popular aceleraría este proceso.

Además de la democratización sustantiva más arriba referida, se constata un segundo cambio, en este caso a nuevos modos de relación Estado-mundo del trabajo: de la represión a la institucionalización, de la exclusión a la incorporación (vide Collier y Collier, 1991). El crecimiento de la clase obrera industrial estuvo directamente relacionado con las políticas estatales y con el crecimiento de empresas estatales desde principios de los treinta (vide Barrera, 1980). De esta manera, el movimiento obrero, y más concretamente el sindical, dirigió sus reivindicaciones no tanto a los empresarios privados como al Estado; de él obtenían la satisfacción de la mayor parte de sus demandas, normal-

4. El liberal Arturo Alessandri fue el último presidente electo de Chile (1920) antes del golpe de Estado.

5. Al triunvirato tradicional de Liberales, Conservadores (representantes ambos de distintos grupos de la clase terrateniente) y Radicales (de las nuevas clases medias) se incorporaron los partidos comunista socialista, creados respectivamente en 1921 y 1933.

6. Manuel A. Garretón se refiere a la democratización como sus tantiva para indicar que el proceso conllevó una inclusión progresiva en el sistema político de distintos sectores sociales, independientemente de que diera lugar a un apoyo instrumental al régimen $(1988,148-9)$

7. El Partido Cristiano Demócrata también ganó las elecciones al Congreso de 1965 
mente vía legislación. Ahora bien, como Ruiz-Tagle ha indicado, "el sindicalismo chileno no sólo representaba los intereses del trabajador asalariado, sino que también defendía a la inmensa mayoría popular, de tal manera que sus esfuerzos trascendían a sus miembros. En su intento por profundizar en la democracia social y económica - continúa-, contribuyó a legitimar la democracia representativa" $(1989,75)$.

El sindicalismo chileno no se desarrolló ni independiente ni autónomamente de los partidos políticos (vide Angell, 1972, II). Por el contrario, fueron éstos — principalmente los de izquierda, pero también los de centro: radical y cristianodemócrata- los que 1) estimularon el desarrollo de las organizaciones sindicales, especialmente nacionales - caso de la Central de Trabajadores de Cbile (1936-1947) y la Central Única de Trabajadores (19521973) —, aunque también promovieron la creación de algunas federaciones y confederaciones ${ }^{8}$, así como los que 2) contribuyeron a legitimar el movimiento sindical. En cuanto a lo negativo de la relación, la alianza entre los partidos políticos y los sindicatos significó muy a menudo la superimposición y confusión tanto de los papeles o cometidos como de los objetivos políticos y económicos.

La llegada a la presidencia chilena de Salvador Allende en 1973 al frente de Unidad Popular reforzó las ligazones entre el gobierno y el movimiento sindical (que de hecho había contribuido sustancialmente a aquella elección), e incrementó en consecuencia el protagonismo de este último en la vida política y económica nacional ${ }^{9}$. Unidad Popular era una coalición predominantemente marxista (compuesta de socialistas, comunistas, radicales y un grupo disidente de cristiano-demócratas) que proponía cambios revolucionarios y el paso al socialismo ${ }^{10}$. Del reforzamiento del vínculo gobierno-sindicatos (Estado-trabajadores) indicado se derivó sin embargo la desestabilización interna de la unidad del sindicalismo, toda vez que la lógica dual de buscar por una parte la transformación del sistema socioeconómico y de centrarse por otra en cuestiones salariales no pareció sostenible por más tiempo, ni en 1972, cuando la inflación se aceleró, ni en 1973, cuando se agudizó la crisis económica.

El gobierno de Unidad Popular no sólo había generado grandes expectativas entre los trabajadores, sino que también había eliminando la represión como instrumento garante del orden social, cuando menos significativamente. En este nuevo contexto, caracterizado por otra parte por una profunda inestabilidad económica y una inflación creciente (quizás consecuencia de los intentos gubernamentales de utilizar instituciones liberal-democráticas para propiciar un cambio social radical) ", se desató una oleada de movilizaciones en demanda de salarios más altos, en gran medida apoyadas y alentadas por los sindicatos cristianodemócratas que, desde dentro de la Central, se oponían al gobierno (vide Valenzuela, 1974) ${ }^{12}$. La polarización política alcanzó tal nivel, en los sindicatos como en la sociedad en general, que su desunión contribuyó a la aceleración de la crisis política. La nación se dividió en las elecciones al Congreso de marzo de 1973 entre un 44\% a favor del gobierno y un $54 \%$ de la oposición. Podría afirmarse que, ante la tensión aparentemente insalvable entre el ejecutivo y el legislativo, y en vista del alto y creciente nivel de movilización social, así como el miedo de las clases capitalistas a perder su poder político y económico, los adversarios de Unidad Popular consolidaron planes para dar una solución militar.

\section{LA DICTADURA DE PINOCHET}

\section{4-1981}

Exacerbadas tensiones entre clases sociales, una profunda crisis social, y, en definitiva, la posibilidad de un Chile marxista en el más inmediato futuro fueron las razones esgrimidas por los militares (tácita o explícitamente aceptadas por las clases medias y superiores) para justificar el golpe de septiembre de $1973^{13}$. Como indica Stephan Haggard (1990) respecto de las intervenciones militares contra regímenes más o menos democráticos, tienen lugar no sólo debido a la preocupación por el desorden y los disturbios, por la inestabilidad política y el ascenso de la izquierda (cuya solución fue la represión), sino también como consecuencia del fracaso de un modelo de desarrollo; su alternativa consistía en promover el crecimiento económico mediante el esquema neoliberal. Y todo ello, continúa Haggard, en el contexto político de una dictadura que en el caso chileno acabó por ser de las más prolongadas y reaccionarias de Latinoamérica ${ }^{14}$.

8. Los sindicatos locales, muy numerosos, fueron pequeños y débiles por lo general (vide Angell, 1972, cap. 3).

9. No se deriva de estas afirmaciones que los dirigentes sindicales hubieran sido nombrados o sugeridos ni estuvieran controlados por el Estado. A diferencia de los movimientos sindicales en Brasil y México por ejemplo, los sindicatos chilenos nunca estuvieron dominados por el Ministro de Trabajo ni por dirigentes del partido o de los partidos en el gobierno (vide Angell, 1972, cap. 4).

10. Drake y Jaksi_ han matizado que esto no significó ningún "cambio repentino de la orientación política", sino que era el resultado de "décadas de paciente construcción de los partidos de izquierda", así como

"la culminación de décadas de expansión del papel del gobierno en la economía y en la sociedad" $(1991,3)$.

11. Es importante tener esto en mente, toda vez que Chile es un buen ejemplo de cómo la crisis económica puede ser atribuida (por parte de los actores no democráticos) a las políticas macroeconómicas expansionistas de los gobiernos que han sido derrocados vía intervención militar (Haggard, 1990, 259).

12. Desde mediados de 1972 tanto las organizaciones de empresarios que representaban a grandes empresas como las que lo hacían a pequeñas recurrieron a tácticas desestabilizadoras del gobierno. Cierres de empresas y huelgas de los transportes provocaron estragos en la economía nacional (Cavarozzi, 1992, 219). De hecho, las fuerzas políticas de centro y de derecha (los cristiano-demócratas y el Partido Nacional) se coaligaron, respaldados por los Estados Unidos, en contra del proyecto socialista de Unidad Popular (Drake y Jaksi_, 1991, 3).

13. Así puede leerse por ejemplo en la "Declaración de Principios de la Junta de Gobierno de Chile”, publicada en la Edición Internacional de El Mercurio del 10 al 17 de marzo de í974, pág. 4.

14. Garretón lo denomina «"nuevo estilo" de régimen militar» (vide 1989, caps. 3 y 5), un tipo de régimen que sufrió el Cono Sur durante más de dos décadas a partir del golpe de estado de 1964 en Brasil, seguido de los regímenes militares argentinos que empezaran en 1966 y en 1976 


\section{Represión}

Algunos autores han observado una naturaleza dual en el carácter de la intervención militar, en Chile como en el resto del Cono Sur (vide Valenzuela y Valenzuela, 1982, y Garretón, 1988 y 1989). En primer lugar, fue reactiva, particularmente reactiva desde un punto de vista comparativo, tanto en intensidad como en alcance y duración. Lo confirman los altísimos niveles de represión y las drásticas medidas que se practicaron para hacer desaparecer por completo el régimen político precedente (vide Fruhling, 1983 y 1984). Con la coerción institucional pretendieron las nuevas autoridades atemorizar y romper la moral, acabar en definitiva con toda y cualquier organización de intereses, ya fuese antigua o nueva, política o social - especialmente las que representaban a los trabajadores, pero también a los profesionales ${ }^{15}$.

Después del golpe la represión no sólo fue masiva, sino también descoordinada, incoherente, arbitraria, vindicativa, dirigida tanto contra los ex-dirigentes de Unidad Popular y sus partidarios como contra los que las nuevas autoridades consideraban sus enemigos. Éste fue el tiempo de los asesinatos y las ejecuciones masivas, de las muertes por tortura y las desapariciones, de la intimidación, el encarcelamiento y el exilio. La represión fue racionalizada, institucionalizada y centralizada bajo el control directo de Augusto Pinochet mediante la creación de la Dirección Nacional de Inteligencia (junio de 1974) y de su sucesora, la Central Nacional de Información (agosto de 1977). En 1980 fue finalmente constitucionalizada.

La represión no consistió tan sólo en violencia física oficial; se trató también de coerción política por decreto que se materializaba en prohibición de los partidos políticos, los sindicatos y otras organizaciones. El nuevo régimen prohibió asimismo la negociación colectiva, y las elecciones sindicales y las reuniones fueron sometidas a un control estricto y extremo. A partir de 1978 impusieron las “modernizaciones", que, de carácter $a d$ boc ${ }^{16}$, afectaron a cuestiones como las relaciones laborales, sanidad pública, educación y seguridad social, entre otras ${ }^{17}$. Hugo Frühling se refiere al periodo 1978-80 como la "Tercera Fase Represiva" de la dictadura, aquella en la cual se diseñó un nuevo cuerpo legal que, al incluir cada acto gubernamental en los límites de la ley, aspiraba a dar más legitimidad al régimen $\mathrm{y}$, adicionalmente, a facilitar la asunción de roles hasta entonces estatales por parte del mercado.

Una clara reacción frente al periodo anterior a la intervención militar, la orientación hacia el mercado significaba, en primer lugar, una disminución significativa de la responsabilidad del Estado sobre los servicios sociales y de su intervención como fuerza impulsora del desarrollo económico y social y como mediador en los conflictos sociales (salvo como legislador excluyente y garante represivo del orden social) ${ }^{18}$. El Estado y el sistema político dejaron de ser espacios relativamente abiertos en los que los trabajadores pudieren defender sus intereses e influir en la dirección del desarrollo. Las intenciones de los dirigentes sindicales de plantear reivindicaciones económicas en nombre de la clase trabajadora y en beneficio de la mayoría de la población fueron calificados como desviaciones políticas o como prentensiones de compartir tareas gubernamentales, ambas inaceptables para el régimen autoritario; en consecuencia, se debilitó sustancialmente el papel que las organizaciones venían desempeñando en la resolución de los conflictos. En segundo lugar, significó, consiguientemente y por el contrario, la acentuación de la primacía de las fuerzas del mercado, es decir, de las empresas privadas nacionales y multinacionales.

La primera "modernización" fue el "Plan Laboral" (1978-1981), un cuerpo de decretos y leyes restrictivos de las relaciones laborales: contratos de trabajo, negociación colectiva, sindicalización y huelgas (vide Ruiz-Tagle, 1985 y 1989). En un contexto donde imperaba el laissezfaire, con el "Plan Laboral" se pretendió atomizar y controlar los sindicatos y debilitar el poder y la efectividad de los trabajadores y sus presiones frente a los empresarios, un cambio radical respecto del proceso de democratización social y económica que caracterizó Chile desde los años veinte.

\section{Neoliberalismo}

Una vez desmovilizada la sociedad civil y política, el régimen dio paso a la segunda tarea más importante que se había impuesto, anteriormente referida: la implantación de un orden nuevo (el elemento represivo continuaba omnipresente). Manuel A. Garretón define esta "dimensión fundacional" $(1989,48)$ como un proyecto que tenía por objetivo reestructurar la sociedad mediante el establecimiento de nuevos mecanismos de acumulación y distribución (según el modelo neoliberal) y mediante el reordenamiento de la política (proceso de institucionalización; vide infra).

El nuevo equipo económico, de tecnócratas, fueron los Cbicago Boys. Dogmáticos e inflexibles ${ }^{19}$, no constreñidos por presión externa alguna merced a la protección que les

y del uruguayo y el chileno, ambos con inicio en el mismo año. Por supuesto, no es ésa la única denominación que han recibido tales regímenes. Desde dictablanda hasta dictadura fascista, los distintos estudiosos han asignado sus propios adjetivos a las dictaduras del Cono Sur. Es probablemente la de “autoritarismo-burocrático" de O’Donnell la que más debate ha suscitado (1973 y 1979. Vide it. Collier, 1979, y Klarén y Bossert, 1986, esp. "Conclusión").

15. El segundo rasgo más destacado que la define es su carácter transformador o regenerador (vide infra)

16. Sólo crisis coyunturalmente relevantes llevaron a la junta militar a legislar sobre los temas que las provocaron, muy en especial cuando tales crisis se producian entre grupos internos del régimen debido a pre siones y amenazas externas, y en cualquier caso siempre de una manera sesgada y personalista.

17. Sobre las "modernizaciones", véanse los mensajes de Pinochet del 11 de septiembre de 1978 y 1979 . Puede encontrarse un informe completo en Chile-América (Roma), no. 74-75, octubre-diciembre, 1981.

18. Como indica Norbert Lechner, el golpe de 1973 definió la situación chilena como un antagonismo de "orden versus caos", que a su vez dio lugar a una "sociedad cerrada" de la cual quedaba excluido "el enemigo” (1986, 126-7).

19. Como Przeworski ha indicado, estos equipos económicos quieren resultados, es decir, estabilidad, solvencia y eficiencia, independientemente de los costes sociales y de las reacciones políticas a que pudieren dar lugar sus medidas $(1991,165)$. 
brindaban las autoridades político-militares (es decir, autónomos en su acción salvo respecto de los directivos de los más poderosos conglomerados chilenos — con los que no había sino sintonía de pareceres-), desarrollaron un proyecto neoliberal radical que consistía básicamente en dos medidas combinadas: estabilización ortodoxa y reestructuración económica ${ }^{20}$. Tenía un carácter dual en cuanto a objetivos, el primero de los cuales era el crecimiento económico mediante una economía de libre mercado orientada a la exportación; el segundo, la aquiescencia, y por lo tanto la disciplina, de los distintos sectores sociales (de los asalariados sobre todo) vía precisamente crecimiento económico ${ }^{21}$.

Chile experimentó un boom económico, en cifras macroeconómicas; devino fuente de legitimidad y prestigio. El PIB creció entre 1974 y 1981 (salvo en 1975); también lo hicieron de manera continuada las reservas de divisas, las exportaciones no minerales y otros indicadores, al tiempo que descendían la inflación y las tasas de interés. Debido al modelo económico aplicado, sin embargo, el sector industrial sufrió una grave crisis. La apertura de la economía a los productos de importación mediante una abrupta reducción de aranceles y una tasa de cambio mantenida baja artificialmente provocó una reducción de la producción industrial desde una cifra de 117,6 por ciento en 1972 al 85,0 de 1975, según el Instituto Nacional de Estadística. Aunque la producción industrial anterior a 1973 fue sobrepasada en 1981, tan sólo llegaron al 129,3, y cayeron al 106,6 por ciento en 1982 (Ruiz-Tagle, 1989, 78).

\section{Efectos sobre los trabajadores y su movimiento}

Como resultado de las dos políticas combinadas (represiva en sentido dual y económicamente neoliberal) ${ }^{22}$, la clase trabajadora se encontró en muy difícil situación para organizarse y funcionar con eficacia en defensa de sus propios intereses como trabajadores y como eventuales ciudadanos. Por otra parte, los sindicatos, impedidos de actuar libremente, habían perdido asimismo un elemento central de su acción: los partidos, sin los cuales se veían incapacitados para facilitar la conexión entre la sociedad y el Estado. En este nuevo escenario, la mayor parte del sindicalismo sobreviviente jugó un papel eminentemente defensivo, esto es, centrado en la defensa legal de sus miembros, en la firma de contratos favorables para los trabajadores, en la denuncia de la represión ejercida sobre las organizaciones y sus dirigentes, etc. Con el transcurso del tiempo emergieron algunos núcleos de liderazgo que jugaron un papel importante en la lucha por el restablecimiento de la democracia. En cualquier caso, estos núcleos desempeñaron básicamente un función simbólica, y no consiguieron hablar en nombre de los trabajadores como un todo.

Durante el periodo que se extendía hasta 1978, las organizaciones sindicales (privadas de sus mediadores naturales - los partidos políticos-y reprimidas con una violencia física extrema) hallaron en la Iglesia Católica chilena un lugar al que recurrir por protección. Esta institu- ción substituyó el lenguaje de los derechos humanos por el de los derechos sindicales y ofreció asimismo un lugar donde los actores sociales y políticos de oposición pudieron reconstituirse (vide Valenzuela y Valenzuela, 1982, 638-40).

La aplicación del Plan Laboral y, más concretamente, la nueva posibilidad de negociación colectiva conllevaron la reactivación del sindicalismo chileno y la legitimación de sus dirigentes a ojos tanto de las autoridades gubernamentales como de los trabajadores. Ahora bien, tal reactivación y reconstitución formal habían de hacer frente a las limitaciones impuestas por el sistema político autoritario en general y por el nuevo código laboral en particular. Como consecuencia, el sindicalismo chileno adquirió inicial y casi exclusivamente un carácter local; garantizaban así su propia supervivencia durante la fase incierta de reproducción y consolidación de sus estructuras internas. Al mismo tiempo, las centrales sindicales y las grandes confederaciones, a las que me referiré más abajo, aspiraron a organizar conflictos limitados, controlados, a fin de presionar sobre el régimen autoritario, y acelerar el retorno a la democracia.

No penetró en los sindicalistas la ideología neoliberal imperante, según la cual los trabajadores obtendrían beneficios - en el nuevo marco legal de relaciones laboralesen la medida en que la economía de mercado funcionara bien. Aquellos que por motivos tácticos buscaron formas de negociación con los órganos estatales pertinentes demandaron, no obstante, la restitución de los derechos laborales perdidos y la vuelta a las formas institucionales de representación existentes en el Chile democrático prepinochetista. El régimen tan sólo consiguió apoyo sindical, limitado y condicional, en algunas empresas estatales, y ello recurriendo a medias de particularismo clientelar. La disponibilidad de fondos para la formación de dirigentes, la asignación selectiva de prestaciones sociales y la resolución parcial de problemas menores posibilitaron el mantenimiento de tales clientelas. Se estima que, de un total de 147 federaciones y confederaciones existentes a finales de 1985, no más del 6,8 por ciento estaban controladas por sindicalistas oficiales u oficialistas; el resto (137 sindicatos) estaba controlado por la oposición (Ruiz-Tagle, 1989).

También los cambios estructurales experimentados en y por la economía afectaron a las condiciones en las que se desarrollaba el sindicalismo. Al menos cuatro efectos prin-

20. Véase Silva (1991) para un análisis sintetizado de las medidas y para una amplia bibliografía específica. Véase Nelson (1990) para un estudio comparativo sobre la elección y la aplicación de los también denominados programas de ajuste por parte de los gobiernos de, en orden cronológico, Pinochet, Seaga, de la Madrid, Rawlings, García y Aquino en Chile, Jamaica, México, Ghana, Perú y Filipinas respectivamente.

21. Carlos Hunneus se refiere a él como un instrumento para conseguir legitimación procedimental o "hacia adelante" (1985, 43-5). Maravall lo denomina también "pacto autoritario" (1993 y 1995).

22. Hay autores que consideran la economía de libre mercado como una manera encubierta de represión vía despolitización de las relaciones de clase. Habermas lo denomina "anonimización de la dominación de clase" $(1975,21)$ y "anonimización política del gobierno clasista" (ídem, 22). El elemento represivo no habría desaparecido; habría sido institucionalizado a través del mercado y de la mercantilización del valor del trabajo (Offe, 1982 y 1984). 
cipales deben ser tenidos en consideración: la reducción en términos relativos de los trabajadores de los sectores minero e industrial, el crecimiento del subempleo y del desempleo, la creciente desigualdad de remuneraciones entre los trabajadores asalariados y, finalmente, la penetración del consumismo entre los mismos: a) Los mineros y los trabajadores industriales encamaban el grupo fundamental del sindicalismo tradicional, pero su presencia porcentual en el conjunto de la fuerza laboral había decaído notablemente. Por el contrario, los grupos laborales que estaban creciendo eran aquellos empleados en el comercio y en otros sectores dinámicos insertos en el nuevo modelo de desarrollo, orientado hacia el exterior. Tales colectivos de trabajadores se caracterizaban por estar aislados en pequeños grupos y por comportarse en gran medida de acuerdo a los valores y formas de las clases medias, aspectos ambos obstaculizadores de la emergencia de un nuevo núcleo sindicalista de peso equivalente al de los centros tradicionales ${ }^{23}$. En cualquier caso, tanto los mineros como los trabajadores industriales seguían ocupando un papel central en la producción ${ }^{24}$ y, más importante, mantenían una influencia muy significativa dentro del sindicalismo. b) Con el aumento del subempleo y del desempleo, disminuyó el poder de los trabajadores en términos de capacidad sindical de movilización y presión, no tanto debido a las dificultades para organizar a las personas que se hallaban en esa situación como por los obstáculos a la organización de acciones de protesta que significaban -en pura lógica racional - tanto la lucha por conseguir un puesto de trabajo como el miedo a perderlo que se derivaría de tal participación ${ }^{25}$. Como indica Ruiz-Tagle "high unemployment has been the most effective means of repression against union activity" (1989, 79). c) La creciente desigualdad de remuneraciones entre los trabajadores según sean de cuello blanco o manuales, con contrato temporal o fijos, etc., toda vez que afectaba a la base del movimiento sindical, también dificultó la acción colectiva. d) A pesar de que los salarios nominales crecieron entre 1975 y 1981, los reales estaban en la última fecha un 3,6 por ciento por debajo de los de 1970 y un 30,2 por ciento por debajo de los de 1972 como resultado tanto del sistema neoliberal de relaciones laborales como de las altas tasas de subempleo y desempleo. Sin embargo, la negativa redistribución de las rentas (vide Ruiz-Tagle, 1989, cuadro 4.1) no fue razón suficiente para propiciar la sindicalización ni la movilización. De hecho, ni siquiera parece haber sido un obstáculo a la penetración del consumismo también entre los trabajadores vía créditos —a pesar de las altas tasas de interés-y mediante horas extras. Cabe indicar adicionalmente que la mayoría de las negociaciones colectivas y las muy pocas huelgas realizadas generaron en los trabajadores implicados un sentimiento de frustración, toda vez que los logros derivados de sus acciones no diferían de los que disfrutaban quienes no habían utilizado la vía de la negociación colectiva. Para Alan Angell, a modo de reflexión en torno a los puntos indicados, una debilidad sustancial de las grandes confederaciones fue

"the fragile contact that existed between the politicized world of the leaders, the major national orga- nizations, and the daily concerns of rank-and-file union members (...). The gap between union leadership and the rank-and-file members weakened the influence of the union movement. One of the major goals of the Pinochet government was to decapitate popular movements and to isolate leaders from their followers" (1991, 193-4).

Los efectos combinados de tales situaciones condujeron a una contracción significativa de las bases del sindicalismo chileno, tanto que casi se paralizaron sus actividades durante los primeros cinco años del régimen militar. La aplicación del Plan Laboral no impidió sin embargo, incluso facilitó, la reconstrucción del movimiento sindical, y no sólo en el ámbito reducido de las empresas. Entre 1977 y 1981 se organizaron cinco grandes sindicatos nacionales (y en consecuencia ilegales) ${ }^{26}$, implicados en actividades también políticas: la Coordinadora Nacional Sindical (CNS), la Central Democrática de Trabajadores (CDT), el Frente Unitario de Trabajadores (FUT), la Confederación de Trabajadores del Cobre (CTC) y la Confederación de Empleados Particulares (CEPCH). Ni aceptaban el nuevo sistema de relaciones laborales - que de hecho denunciaban radicalmente- ni por supuesto el régimen autoritario, pero aprovecharon las ventajas derivadas del espacio abierto por la dictadura para luchar por una recuperación del poder adquisitivo de los trabajadores y por la vuelta a la democracia.

Como Ruiz-Tagle ha indicado $(1989,87)$, los empresarios aparecían no sólo como adversarios que presionaban merced a su poder económico, sino también como jefes que tenían a su servicio el régimen militar, es decir, sus estructuras legales y sus cuerpos represivos. Esto impulsó la formación de conciencia de clase y la unidad de acción entre (los) trabajadores, especialmente en el ámbito de las empresas, el único en el que la negociación colectiva era legal. (Los) trabajadores, manuales o de cuello blanco, se percibían a sí mismos como una clase económica, política, legal e incluso físicamente reprimida por la dictadura; de ahí que estuvieran dispuestos de alguna manera a manifestar abiertamente su protesta cuando fuera posible. Virtualmente desaparecidos los partidos de la arena política como mediadores entre la sociedad civil y el Estado, fueron los sindicatos los que asumieron tal papel; de ello se derivó un proceso de politización creciente de las propias organizaciones. Ahora bien, el movimiento obrero, organizado o no, no fue en momento alguno un desafío a la exis-

23. Respecto a la composición de la clase trabajadora, Paulo Hidalgo (1991) señala su envejecimiento relativo como un factor adicional, si bien no argumenta la conexión explicativa.

24. A pesar de su reducción en tamaño, el Estado mantenía su control sobre la producción a gran escala de cobre, petróleo, carbón y acero.

25. Según la Ley Laboral, durante una huelga el empresario podía contratar a cualquier trabajador que considerara necesario. Así mismo, el régimen autoritario - con el pretexto aducido de facilitar la movilidad laboral- estableció la posibilidad de despedir trabajadores sin justificación alguna, eliminó las normas que limitaban los despidos colectivos y facilitó un incremento del número de contratos temporales.

26. El Plan Laboral no permitía la creación de centrales nacionales. 
tencia ni a la continuidad de la dictadura durante el período de tiempo aquí considerado.

\section{Institucionalización del Régimen}

Como se vio al hacer referencia a las "modernizaciones", el hecho de que los objetivos más inmediatos del primer momento estaban cumplidos (la invocación a principios de guerra o a la presencia de un enemigo exterior ya no eran suficientes argumentos legitimadores), la preocupación creciente de los sectores que inicialmente habían apoyado la instauración de un gobierno militar en cuanto a la "regularización" del régimen, así como la también creciente presión por parte de entidades e instituciones nacionales - caso de la Iglesia - e internacionales, determinaron a Pinochet a favor de la definición de las reglas y normas del régimen a finales de los setenta.

Pinochet aprobó en 1980 una nueva Constitución; así lo hicieron también los chilenos mediante un segundo plebiscito no competitivo ${ }^{27}$ caracterizado tanto él como el periodo preelectoral por una gran cantidad de irregularidades ${ }^{28}$. Se promulgó al año siguiente. Estaba diseñada para asegurar la continuidad del régimen autoritario y del mandato de Pinochet, al menos hasta 1988; entonces debería celebrarse otro plebiscito: los comandantes de las fuerzas armadas propondrían un candidato (Pinochet no fue ni esperaba ser excluido de tal elección) para que la ciudadanía lo aprobara o rechazara para una presidencia de ocho años. Para Cavarozzi, siguiendo a O'Donnell y Schmitter (vide 1986, 9), el proyecto transformaba el régimen en una dictablanda.

"An extended process of political liberalization would be controlled from above for at least another fifteen years, thus allowing the authoritarian government to complete the structural reform of the Chilean economy and society initiated in the 1970s" (Cavarozzi, 1992, 223),

Opino que es más correcto el análisis de Manuel A. Garretón. Como él indica, durante los setenta y los ochenta las dictaduras del Cono Sur - es decir, los bloques dominantes, y más concretamente los núcleos hegemónicosbuscaron principios legitimadores distintos de aquellos basados en la seguridad nacional e incluso en la reconstrucción y consolidación capitalista $(1988,152)$. Aspiraban al establecimiento de un proyecto político, necesitaban la institucionalización política de sus propios regímenes ${ }^{29}$. Así, Pinochet habría abierto un proceso de transición de un régimen militar a uno autoritario en el cual el ejército no monopolizaría el poder político formal, pero sí estaría bajo su tutela. Asimismo, a pesar de que se establecerían algunos mecanismos de participación, éstos estarían combinados con autoritarismo estatal y con mecanismos de exclusión institucionalizada. El objetivo era aunar políticamente la visión de la sociedad como un mercado y los principios de la "seguridad nacional", que reafirman la visión autoritaria de la sociedad (Garretón, 1988, 168).

\section{2-1988}

El régimen militar aspiraba a que tanto el modelo económico neoliberal como el mandato autoritario de Pinochet se extendieran durante al menos las dos décadas que restaban hasta la finalización del siglo. Tanto los resultados económicos como los del plebiscito de 1980 justificaban tal expectativa por parte de la élite dominante, y muy concretamente de la Junta. No obstante, la crisis económica de finales de 1981 a 1983 puso en cuestión su euforia, e incluso forzó un cambio de políticas radicales a pragmáticas, sin dejar de ser neoliberales ( $c f r$. Silva, 1991). Ello fue así no sólo por razones económicas, sino también por motivos políticos, es decir, derivados de un análisis en términos de grupos sociales de oposición tanto internos al régimen o disidentes (en especial los grandes empresarios y terratenientes, quienes clamaban por medidas deflacionarias y sectoriales específicas) ${ }^{30}$ como desde fuera del bloque dominante, desde la sociedad civil, y más concretamente por parte de las clases inferiores: trabajadores remunerados y habitantes de los suburbios o barrios de chabolas.

Chile conoció entonces la peor depresión desde 1930. Como resultado de las reducciones salariales ${ }^{31}$, los salarios reales cayeron del 102 por ciento en $1982(1970=100 \%)$ al $91 \%$ en 1983 y al $87 \%$ en 1985 . La tasa de desempleo creció del 8,1 al 28,2\% entre septiembre de 1981 y diciembre de 1983. Las cifras fueron más elevadas en los sectores económicos de la construcción e industrial, donde tenían su razón de ser el sindicalismo antes del golpe (vide Hunneus, 1985).

27. Augusto Varas ha señalado cómo ninguna dictadura de la región ha escapado a la necesidad de legitimarse mediante elecciones o plebiscitos, ya fuera para perpetuarse, ya para asegurarse una sucesión favorable (1991, 73). El primer plebiscito pinochetista se celebró en 1978 como respuesta a las críticas internacionales contra las atrocidades que estaba cometiendo el régimen en contra de los derechos humanos en Chile. Controlando e interfiriendo, la junta militar obtuvo un apoyo del 75 por ciento.

28. A pesar de este hecho, el triunfo gubernamental demostró la capacidad de desarticulación social del régimen, su efectividad en la creación de miedo tanto a la represión como al pasado, su habilidad para generar dudas respecto de la existencia y viabilidad de alternativas políticas y, en fin, su capacidad para provocar conformismo pasivo, todos ellos obstáculos no institucionales al desarrollo de la oposición, que parecía carente de poder alguno y confusa, "intimidada, temerosa, fragmentada e impotente" (Drake y Jaksi_, 1991, 6).

29. De hecho, afirma que cuando los distintos sectores de la coalición chilena dominante debatieron respecto del régimen político, ninguno de ellos cuestionó su carácter autoritario ni habló de "liberalización" de acuerdo a la conceptualización de O’Donnell y Schmitter. Por el contrario, tales sectores se polarizaron acerca de si había de ser o no un régimen militar (Garretón, 1988).

30. Si bien considero a estos grupos sociales como del o internos al régimen (es decir, partidarios de Pinochet, y en consecuencia sectores de la coalición dominante), no entiendo que sean "los poderosos" (the powerful) a que alude Haggard (1990, 264), quienes serían más específicamente los conglomerados, el "equipo económico" y por supuesto el mismo Pinochet. La Junta no había prestado atención a las demandas de aquellos hasta que el régimen se vio acosado por $-\mathrm{O}$ al menos en presencia de- movilizaciones de masa desestabilizadoras.

31. Ésta fue una de las principales proposiciones que los Chicago Boys habían venido haciendo a la Junta desde el principio, mas los militares no consintieron hasta 1982, fecha en que accedieron a abrogar la cláusula de ajuste salarial del código de trabajo de 1979 por la cual se garantizaba el 100 por cien del poder adquisitivo de los asalariados (vide Edwards, 1985) 


\section{Movimientos de protesta}

El colapso de la economía chilena provocó masivas protestas sociales entre 1982/83 y 1985. Durante al menos tres años, pese a que las movilizaciones no derrocaron el gobierno, cuando menos lo desestabilizaron en la medida en que desafiaron el carácter políticamente muy limitado —en términos democráticos- del proceso de institucionalización. Fueron iniciadas por los trabajadores organizados, y más concretamente por los mineros.

Según algunos autores, la depresión económica determinó en los trabajadores, y más concretamente en los sindicalistas, un cambio significativo de una actitud en gran medida defensiva y orientada en sus acciones a la recuperación del poder adquisitivo a una toma de conciencia de su situación en tanto que clase oprimida y reprimida. El movimiento obrero se habría politizado y puesto por metas el cambio de la política neoliberal y la sustitución del régimen autoritario que la sostenía. Arturo y J. Samuel Valenzuela, por el contrario, piensan que los sindicalistas no habían estado despolitizados, sino tan sólo desmovilizados $(1982,637)$. No obstante su plausibilidad, como no se refieren a los trabajadores, sino a los dirigentes y militantes, pienso que ambos argumentos pueden combinarse, máxime si tenemos en consideración, por una parte, el éxito referido de la estrategia de Pinochet para aislar a los dirigentes opositores de sus reales o potenciales seguidores y, por otra, que también las clases medias - cuando menos tácitos apoyos del régimen hasta entonces- se vieron igualmente politizadas y movilizadas. Éste es el contexto en el deben analizarse las llamadas a los días de protesta entre marzo y abril de 1983, no sólo reducida a los mineros desde la CTC a partir de entonces.

El llamamiento a la huelga general de trabajadores, ampliamente respaldado, al tener que hacer frente a las respuestas represivas del régimen, fue reemplazado por un llamamiento al día nacional de protesta, que incluía además a los habitantes de los suburbios, a los estudiantes, a los profesionales e incluso a los empresarios, a todos aquellos en quienes las preocupaciones respecto de la aguda crisis económica se combinaban con - resultaban en- el deseo por una salida democrática a la situación. El éxito de las convocatorias -incluso amplios sectores de la clase media se incorporaron rápidamente a las acciones colectivasevidenció la amplia capacidad movilizadora del movimiento sindical, y consecuentemente su fuerza (no obstante los bajos niveles de las cifras oficiales, caso del de afiliación [vide Ruiz-Tagle, 1989]). El movimiento sindical devino un actor social colectivo subversivo y desestabilizador para una dictadura que había abierto un proceso no finalizado de institucionalización. Como ha indicado Ruiz-Tagle, "the union movement thus became the cement binding different social forces that had been passive, or that earlier acted in a disorganized way" $(1989,90)$. No se trataba tan sólo de que la legitimidad procedimental ansiada por las autoridades se viera severamente erosionada, sino también de que la mayoría de los chilenos empezaban a pensar que también económicamente - valoraciones políticas eviden- tes aparte- habían estado mejor antes del golpe, o al menos así parece atestiguarlo un sondeo de opinión (vide Hunneus, 1985, 55-6).

\section{Desmovilización}

Con el plebiscito de 1988 en mente, Pinochet se veía compelido a poner fin al desorden social. Pero el control político-militar, esto es, la represión física de la oposición externa al bloque dominante - no obstante haberse empleado con crudeza - no podía ser suficiente para crear las condiciones electorales favorables necesarias para permitirle ganar la próxima y constitucional convocatoria plebiscitaria - el último paso en la transición a la institucionalización del régimen - sin recurrir a fraude electoral alguno. El dictador pensó que también debía hacerse con la aquiescencia de los grupos localizados en las zonas altas y medias de la jerarquía social, incluso - probablemente en menor medida - de las bajas; para ello había de propiciar la recuperación económica en términos de crecimiento estrictamente económico, pero también de empleo. Sería su segundo instrumento más importante para la estabilidad política, económica y social, toda vez que se recuperaría la confianza y lealtad del sector privado (vía incorporación en el modelo radical de los ajustes pragmáticos demandados por la nueva coalición capitalista) ${ }^{32}$ y ayudaría a reducir el movimiento de protesta, como de hecho ocurrió — ambos objetivos-hacia $1985^{33}$. Adicionalmente, como los chabolistas o pobladores (ligados a los partidos Socialista y Comunista) acabaron por dominar aquellas manifestaciones, violentas en ocasiones, los opositores a la dictadura de clase media dejaron de secundar las movilizaciones, temerosos de acciones radicales o rupturistas de izquierda. De nuevo, como en el momento del golpe militar y como suele ocurrir (vide Huntington, 1991), las clases medias respal-

32. Las políticas económicas se caracterizaron temporalmente por un equilibrio entre estabilización económica y medidas estructurales, por una parte, y las necesidades de los empresarios por otra; es decir: un equilibrio entre la creación de una economía abierta y el mantenimiento de la protección de los que producían mayormente para los mercados domésticos. Hacia 1985, sin embargo, la oposición estaba bajo control y el régimen había retornado a una versión ligeramente modificada de su estrate gia aperturista, orientada al mercado. Como Francisco Orrego concluye, el apoyo del empresariado es básicamente una cuestión de "conveniencia"; su interés preeminente es la preservación de sus propiedades y la creación de las condiciones necesarias para la estabilidad política y económica en la que trabajar con seguridad $(1985,151 ; v$. Varas, 1991, 88-9). No sólo se aplicaron las medidas económicas que sugirieran, sino que incluso se les permitió participar a través de sus asociaciones en la elaboración de aquellos decretos, ordenanzas y leyes que les afectaran con motivo de su actividad económica. Les fueron asimismo ofrecidas algunas posibilidades de oposición organizada —una muy limitada liberalización política-, como podría atestiguar la acción del Partido Nacional de no ser porque acabó disolviéndose como muestra de su apoyo al régimen. Véanse Hunneus (1985) y Silva (1996) para más información sobre esta apertura.

33. A pesar de que el número de trabajadores en huelga y la duración y cantidad de huelgas se incrementó positivamente entre 1984 y 1985 - posiblemente un indicador del aumento de la actividad sindical-, debe tenerse en cuenta que los trabajadores implicados en 1985 correspondían a tan sólo un 0,24 por ciento de la fuerza de trabajo empleada y un 5,8 por ciento de los afectados por negociaciones colectivas. Ruiz-Tagle señala las restricciones legales como la causa principal (1989, cuadro 4.5) 
daban o preferían el mandato autoritario en condiciones de polarización social y amenaza ${ }^{34}$.

Desde un punto de vista macroeconómico, la economía chilena evolucionó muy bien. En un contexto internacional favorable, el PIB creció, las tasas de interés fueron relativamente bajas y los déficits fiscales bajos, las relaciones comerciales aumentaron, la inflación se mantuvo en niveles inferiores a los de la media latinoamericana, cayó el desempleo del 23 por ciento en 1984 al 14 por ciento en 1988 e incluso los salarios reales crecieron (de un índice del 87 por ciento en 1985 al 94,5 de 1988 [Silva, 1991; vide Larraín, 1991, 278-81 y cuadro 9.3]).

Alan Angell (1991) ofrece una tasa de desempleo inferior para $1988-11,2 \%-$, pero enfatiza asimismo los costes sociales, la extremadamente creciente desigual distribución de la renta, derivada del modelo de crecimiento económico. Los salarios se recuperaron menos que la economía en su conjunto durante el periodo de crecimiento que siguió a 1985. Después de crecer, el salario real medio se mantenía en 1988 al nivel de 1980, un 5 por ciento por debajo del de 1970 (vide Larraín, 1991, cuadro 9.2). El salario mínimo legal había caído más entre 1982 y 1986, y subido menos desde entonces ${ }^{35}$. Si tenemos así mismo en consideración la tasa de desempleo y el carácter crecientemente informal, inestable, temporal e incluso irregular — subcontratadodel empleo, tiendo a pensar que no se trata tanto de "indicators that demonstrates the lack of union power against a hostile government" (Angell, 1991, 190) como de razones que, de nuevo, ayudaron a desmovilizar y debilitar el movimiento obrero, al menos en tanto que amenaza o preocupación para la dictadura. Finalmente, Alan Angell analiza el trabajo femenino como un obstáculo a la actividad sindical eficaz (1991, 190-2). Como indicara más arriba, el modelo de crecimiento acentuó el proceso de marginación, segmentación y fragmentación y fomentó la penetración del "consumismo" también entre los trabajadores, incluso a pesar de lo elevado de los créditos. Estos dos aspectos, combinados con la práctica desaparición del Estado como objeto de la acción colectiva debido a la drástica disminución de su intervecionismo en el ámbito de lo económico, dieron lugar, nuevamente, a que movilizarse por objetivos comunes fuera extremadamente difícil.

Además de la represión y de la recuperación económica en los términos analizadas, un último elemento: el vínculo con los partidos políticos por parte del movimiento sindical, ayuda a comprender por qué éste no pudo ni asumir abiertamente el liderazgo de la lucha contra el régimen a través de las masivas movilizaciones, ni por supuesto derrocarlo. La magnitud de las protestas obligó al régimen a abrirse políticamente. No obstante tratarse de una apertura muy limitada, fue suficiente para permitir a los partidos, muy debilitados e incluso en gran medida desarticulados (vide Garretón, 1991), iniciar la reconstrucción de sus estructuras orgánicas y la construcción de bloques de oposición a finales de 1985: Alianza Democrática (de centro-izquierda, encabezada por los cristiano-demócratas), Movimiento Democrático Popular (de izquierda, con el
Partido Comunista al frente) y Acuerdo Nacional, que agrupaba sectores de todo el espectro político.

El movimiento sindical no puede entenderse sin referencia a los partidos políticos. De hecho, Arturo y J. Samuel Valenzuela (1982) sostienen que éstos se habrían esforzado por estar presentes y activos en el seno de los sindicatos, que los habrían utilizado en tanto que organizaciones desde las cuales mantenerse en contacto con, e influir sobre, la sociedad civil, no obstante (y debido a) la dictadura, incluso gracias al régimen. De esta manera, a partir de 1986 ó 1987, quizás incluso antes, el movimiento sindical devino reflejo de las divisiones propias de los bloques políticos y los partidos al mismo tiempo que les cedía el liderazgo de la lucha en Chile por la vuelta a la democracia y perdía parte de la autonomía relativa que había alcanzado en el periodo anterior. Ruiz-Tagle (1986) afirma que las centrales chilenas se vieron forzadas a recurrir a los partidos más de lo que hubieran deseado, y que asimismo se apoyaron en gran medida - y en mayor medida que hasta entonces- en la solidaridad internacional, ayuda que a su vez parece haber venido aparejada a ciertas condiciones moderadoras de su actividad y reivindicaciones (Angell, 1991). Los partidos no eran especialmente fuertes; tampoco se trató de que estuvieran en condiciones de aportar muchos beneficios a quienes los apoyaran; más bien, lo que ocurrió fue que los sindicatos estaban internamente tan divididos respecto de los objetivos y tan presionados y constreñidos desde fuera que probablemente no podían hacer otra cosa sino reforzar el papel de los partidos. En cualquier caso, la desunida oposición política no era en modo alguno una alternativa a la dictadura ${ }^{36}$, y no pudo romper el proceso de transición diseñado por Pinochet en favor de una democratización real ni más rápida.

De acuerdo a la expresión de Eduardo Silva, el régimen de Pinochet "had weathered the storm" $(1991,113)$.

34. El argumento no es nuevo en modo alguno. Aparte de haberse utilizado para explicar las elecciones que dieron pie al ascenso al poder del nazismo, ya los anarquistas afirmaron a principios del siglo XX que "si el gobierno adoptase una actitud hostil, si la 'democracia' pudiera ser otra cosa que un medio de engañar al pueblo, la burguesía, amenazada en sus intereses, se aprestaría a la rebelión sirviéndose de toda la fuerza y de toda la influencia que la posesión de la riqueza le proporciona para reducir al gobierno a la función de simple gendarme puesto a su servicio" (Malatesta, 1904, en Horowitz, 1975, 95).

35. Coincido con Drake y Jaksi_en que, como durante 1977/81, «it was perhaps no accident that the main victims of the [new] economic "miracle" were also the main political enemies of the regime, the urban workers» $(1991,5)$. Pamela Constable y Arturo Valenzuela respaldan esta idea afirmando que el innegable éxito macroeconómico fue alcanzado reprimiendo e ignorando las demandas públicas de igualdad social $(1989 / 1990,182)$. Para un análisis de las políticas sociales "hacia la extrema pobreza" del régimen pinochetista, véase Vergara (1990); la autora las ha puesto asimismo en comparación con las aplicadas en la fase de democratización (1993 y 1994; vide Maravall, 1995, esp. 44 ss. y 81 ss.).

36. Los distintos partidos y bloques políticos discrepaban entre ellos tanto respecto del régimen socio-económico por el que estaban luchando como por las estrategias que deberían utilizar para alcanzarlo. De hecho, estaban más preocupados por la identidad de quienes formarían parte y quienes no de un frente único que por los términos de una eventual propuesta unitaria con la que hacer frente a la dictadura (vide Gaspar, 1988, y Garretón, 1991). Por otra parte, el régimen consiguió que los partidos de oposición de centro se alejaran de las tácticas de confrontación directa. 
Pinochet pudo y supo evitar el colapso del régimen cambiando lo que estimaba necesario desde un punto de vista estrictamente pragmático para asegurar su supervivencia sin afectar la naturaleza de su mandato, como demuestra por ejemplo su negativa a alterar la legislación laboral. El plebiscito de 1988 seguía siendo un instrumento para consagrar y prolongar - en modo alguno para acabar con- el régimen autoritario. Desde principios de 1987 la dictadura continuó firme en su proceso de institucionalización política. Fueron promulgadas algunas leyes restrictivas que completaban la Constitución (sobre partidos políticos, registro electoral, votos y recuento de votos, etc.) y se convocó a la población para registrarse en las listas electorales.

Para Garretón (1991), la oposición entendió, percibió finalmente que el régimen no vería su fin ni por colapso ni por derrota; tan sólo y en todo caso, mediante un proceso político. Consiguientemente, tenían que unirse (como hicieron en febrero de 1988) para hacer frente a una confrontación política institucionalizada, es decir, para precipitar la transición a la democracia política mediante el plebiscito. Esto aisló y debilitó a los grupos que favorecían la confrontación armada con la dictadura. Aunque los comunistas no se integraron en la Concertación por el NO, finalmente acordaron también ellos hacer un llamamiento para votar "no" (junio de 1988).

Los sindicatos se reconstituyeron lentamente. En agosto de 1988 el mayor grupo del movimiento sindical (las centrales de izquierda y sus aliados democristianos) se unió en una gran confederación, la Central Unitaria de Trabajadores (CUT), pretendida heredera de la anterior. Pero, como la $\mathrm{CNT}^{37}$, la nueva CUT era más el resultado de un acuerdo político que de cuestiones sindicales. Se formó, en palabras de Alan Angell, "because the political moment was propitious, the parties with power in the union movement were in agreement, and such agreement was functional to the strategy of the political opposition" (1991, 198). Consiguientemente, los partidos y las organizaciones sociales (no sólo la CUT, sino también otras de independientes, empresarios, etc.) se reforzaron mutuamente al superar las tensiones y las contradicciones del pasado. Los sindicatos defendieron con vigor el "no" en el plebiscito y apoyaron a Aylwin como candidato presidencial, al tiempo que se plegaban (por incapacidad o por decisión propia, cualesquiera que fuesen los motivos) a las consignas no movilizadoras emanadas de la coalición política (y del gobierno en su momento) a fin de garantizar la estabilidad del proceso democrático (vide Rojas Hernández, 1993).

\section{Resultados del plebiscito y conclusiones}

No obstante haber desmovilizado y debilitado los sindicatos y el movimiento obrero directa o indirectamente, tal y como he defendido en el apartado precedente, el régimen fracasó en su intento de conseguir apoyo suficiente. Coincido con Augusto Varas cuando asevera que "even if a military government can efficiently structure a closed and noncompetitive political system, it still is ineffective in generating a legitimate, non-authoritarian system for the distribution of goods, services, and political power" (1991, $75)^{38}$ La transformación económica chilena no había repercutido en términos parangonables sobre muchas familias pobres y de clase media. Además, también eran muchos los chilenos que mantenían vivo su resentimiento por los años de humillación y represión. Los partidos de oposición se comprometieron con la política neoliberal practicada en términos macroeconómicos incluso durante la campaña plebiscitaria; no obstante, y como se esperaba de ellos, enfatizaron los temas distributivos (vide Varas, 1991, cuadro 2.1, y Alaminos, 1991, esp. 134-7).

La oposición sabía lo que los sondeos de opinión pública confirmaban: la mayoría de los chilenos deseaban el cambio político, pero en condiciones de orden y estabilidad, y su unidad era el aspecto más valorado durante la campaña. La oposición ganó el plebiscito el 5 de octubre, y se dio paso a una transición plena a un régimen de democracia competitiva. El dictador, cualesquiera que fuesen los motivos, aceptó su derrota, y permito la apertura de un proceso electoral para comicios parlamentarios y presidenciales en lugar de aferrarse violentamente al poder. Los esfuerzos de los grupos de oposición para trabajar juntos aportaron la base para la formación de una única lista para las elecciones de 1989. Así, como en Brasil (vide Mainwaring y Share, 1986), se creó un gran frente de oposición electoral. El Partido Demócrata Cristiano fue el núcleo de la nueva Concertación de Partidos por la Democracia (CPD), constituida por diecisiete partidos; cristianodemócrata fue así mismo el candidato presidencial, Patricio Aylwin, quien ganó las elecciones. La transferencia de poderes se realizó en marzo de 1990.

No es suficiente decir "the union movement was not a critical actor in the mobilization of the opposition that led to Pinochet's defeat in the plebiscite" (Angell, 1991, 207). Se requiere analizar sus implicaciones. Tiendo a pensar, tal y como he argüido a lo largo del trabajo, en primer lugar, que el movimiento obrero a principios de los ochenta - por su propia movilización y politización, pero también por aquella a la que daba lugar- tuvo al menos dos efectos importantes sobre el régimen y sobre el posible comienzo de la transición: a) obligó a la dictadura a transformarse vía apertura política y (consecuencia no intencionada) a entrar en un proceso bien distinto del

37. Las cinco grandes centrales sindicales creadas después del golpe (vide above) se integraron en una única de ámbito nacional en mayojunio de 1983: el Comando Nacional de Trabajadores, bajo el liderazgo de los mineros del carbón. Organizó algunas manifestaciones y otras acciones colectivas en defensa de los derechos sindicales y de la vuelta a la democracia formal. Pero la CNT no fue más que una entidad difuminada de coordinación, y la eventualidad de constituirse en voz e instrumento protagonista de la oposición se vio debilitada por las disputas entre los miembros que la constituían. Oficialmente fue la base de la nueva CUT.

38. Acerca del carácter subóptimo de los regímenes autoritarios, véase O'Donnell (1979). En cuanto a su “inefectividad", debe tenerse en cuenta que no es una cuestión de falta de capacidad, sino de carencia de voluntad, es decir, derivada del carácter sesgado de estos regímenes. Un estudio interesante sobre este tema, centrado en el caso español, en el régimen franquista, puede encontrarse en Gunther (1980). 
previsto por Pinochet, que se le volvió en contra (vide O’Donnell y Schmitter, 1986, 11, y Linz y Stepan, 1990, 48); b) al mismo tiempo, las acciones colectivas de protesta abrieron el espacio para la reemergencia de los partidos políticos, y así para su victoria en el plebiscito. La fase transicional de institucionalización devino finalmente de liberalización, y el referéndum no fue la llave para la consolidación de la dictadura -independientemente de que para entonces pudiera considerársele ya un régimen autoritario propiamente dicho o no--, sino para la democratización del país ${ }^{39}$.

En segundo lugar, y en relación al carácter de la transición, el papel del movimiento obrero durante el plebiscito y las elecciones - en tanto que desmovilizado y no desafiante del status quo- fue tan importante como los días de protesta. Pese a las protestas masivas y las manifestaciones de 1983-1985 que casi paralizaron el país, la dictadura siguió siendo una realidad, en parte porque no existía una alternativa política unitaria y coherente. Hacia 1988, a pesar de haberse unido la oposición a partir del rechazo del candidato de las fuerzas armadas, las acciones colectivas parecían inexistentes. A partir de la comparación de este cambio de régimen con el español de los setenta, entiendo que debido a tal desmovilización la oposición chilena permitió a la dictadura, es decir, no pudo impedir que Pinochet impusiera límites a una transición que garantizaba una posición satisfactoria a los que hasta entonces detentaban el poder político-militar una vez fueran conocidos los resultados del plebiscito ${ }^{40}$. La transición chilena se ha convertido, así, en la transferencia de poder más "desleal" (disloyal [Linz y Stepan, 1990, 48]) de las acaecidas en Europa del Sur y en el Cono Sur de América Latina. El gobierno entrante tuvo que acceder a gobernar con la Constitución del régimen autoritario, y, parcialmente enmendada en 1989, intentar eliminar sus características autoritarias haciendo uso de los difíciles procedimientos que en ella misma se estipulaban.

Por supuesto, mi segundo objetivo no ha sido afirmar que las movilizaciones hubieran asegurado una transición plena a la democracia política, es decir, una democratización sin constricciones. Tanto podrían haber acelerado un final de la dictadura menos controlado desde arriba como, por el contrario, haber propiciado una indeseable reacción represiva e involucionista. Mi pretensión ha sido, contrariamente, hacer notar la importancia de su ausencia durante la segunda mitad de la liberalización en la definición del tipo de democratización que ha tenido lugar en Chile, un factor complementario y adicional a aquellos argüidos por los autores de la perspectiva elitista o de la contingencia. En resumen, entiendo que el hecho de que la desmovilización se hubiera dado no sólo durante la democratización - como afirman los investigadores referidos-, sino también durante la liberalización desde 1985/86, aligeró el coste para las autoridades dictatoriales de una transición muy controlada desde arriba.

\section{REFERENCIAS BIBLIOGRÁFICAS}

Alaminos, Antonio (1991): "Chile: Transición Política y Sociedad". Madrid: Centro de Investigaciones Sociológicas.

Angell, Alan (1972): Politics and the Labour Movement in Chile. London: The Royal Institute of International Affairs, Oxford University Press.

- (1991): "Unions and Workers in Chile during the 1980s", in Drake, Paul W. \& JaKsIC, Iván (eds.): The Struggle for Democracy in Chile, 1982-1990. Lincoln and London: University of Nebraska Press. Pages 188-210.

BARrera, Manuel (1980): "Desarrollo Económico y Sindicalismo en Chile: 1938-1970". Revista Mexicana de Sociología, vol. 42, $\mathrm{n}^{\circ}$ 3, Julio-Septiembre. Págs.1269-96.

Cavarozzi, Marcelo (1992): "Patterns of Elite Negotiation and Confrontation in Argentina and Chile", in Highley, John \& GunTHER, Richard (eds.): Elites and Democratic Consolidation. Cambridge: Cambridge University Press. Pages 208-236.

Collier, David (ed.) (1979): The New Authoritarianism in Latin America. Princeton, N. J.: Princeton University Press.

Collier, Ruth \& Collier, David (1991): Shaping the Political Arena. Critical Junctures, the Labor Movement, and Regime Dynamics in Latin America. Princeton, N. J.: Princeton University Press.

Constable, Pamela \& Valenzuela, Arturo (1989/90): "Chile's Return to Democracy". Foreign Affairs, vol. 68, $n^{\circ} 5$, Winter. Pages 169-186.

DiAmOND, Larry \& Linz, Juan J. (1989): “Introduction: Politics, Society, and Democracy in Latin America”, in DiAmOND, Larry; LinZ, Juan J. \& LiPSET, Seymour M. (eds.): Democracy in Developing Countries: LatinAmerica, vol. 4. Boulder, C. O.: Lynne Rienner.

39. En cuanto al renacimiento de los partidos políticos después de 1982, probablemente no se viera causado ni facilitado por el movimiento obrero. Existe la hipótesis alternativa de que los partidos habían utilizado a los sindicatos tanto durante la fase previa como durante la posterior a las protestas (vide Valenzuela y Valenzuela, 1982). Ambas hipótesis debieran contrastarse empíricamente.

40. También en España tuvo lugar la desmovilización durante la transición, pero a) se trató de una desmovilización política, no económica, y b) tuvo lugar en la segunda parte de la fase de democratización, una vez el carácter plenamente democrático del nuevo régimen constitucional estaba asegurado vía consenso. Como Maravall ha indicado, la presión popular desde abajo, $y$ más concretamente la del movimiento obrero, fue un elemento crucial en el proceso de cambio de régimen en al menos cuatro aspectos fundamentales: contribuyó a la crisis de la dictadura; hizo inviable la democracia controlada, a la española, de Arias Navarro; forzó a los reformistas del régimen a negociar y democratizar, y, en fin, reforzó a la oposición de izquierdas en su relación y negociación con el gobierno reformista de Suárez (1985, I.1). En España hubo un bloque político de oposición alternativo al régimen autoritario: Coordinación Democrática o Platajunta, como en Chile, pero existió también una creciente y en algunos momentos desestabilizadora y amenazante conflictividad y movilización social (de trabajadores sobre todo) que hizo ver la inevitabilidad del consenso a parte del gobierno - y así del régimen — si se quería evitar una portugalización del proceso. 
DrAKE, Paul W. \& JAKSIC, Iván (1991): "Introduction: Transformation and Transition in Chile, 1982-1990", in DRAKE, Paul W. \& JAKSIC, Iván (eds.): The Struggle for Democracy in Chile, 1982-1990. Lincoln and London: University of Nebraska Press. Pages 1-17.

Duran MuÑoz, Rafael (1997): "Movilizaciones obreras y transiciones políticas. Portugal y España”. Ponencia presentada para ser debatida en el Seminari de Sindicalisme $i$ Transició Política a Espanya: el sindicalisme de nou tipus en la transició. Fundació Cipriano García, Arxiu Histbric, CONC, Barcelona, Enero.

EDwards, Sebastian (1985): "Economic Policy and the Record of Economic Growth in Chile, 1973-1983”, in Walton, Gary M. (ed.): The National Economic Policies of Chile. Greenwich, Conn.

EPSTEIN, Edward C. (1989): "A Historical Introduction", in idem (ed.): Labor Autonomy and the State in Latin America. London, Sydney, and Wellington: Unwin Hyman. Pages 1-11.

Field, G. Lowell \& Higley, John (1980): Elitism. London: Routledge \& Kegan Paul.

FrüHLING, Hugo (1983): "Strategies of Repression and Legal Strategy for the Defense of Human Rights in Chile: 1973-1980". Human Rights Quaterly, vol. 5, $\mathrm{n}^{\circ} 4$.

- (1984): "Repressive Policies and Legal Dissent in Authoritarian Regimes: Chile 1973-1981". International Journal of the Sociology of Law, 12. Pages 351-374.

FríAs, Patricio (1986): Prácticas y Orientaciones del Movimiento Sindical en la lucha por la Democracia. Santiago: PET.

Garretón, Manuel A. (1988): “La Evolución Política del Régimen Militar Chileno y los Problemas en la Transición a la Democracia”, en O'DONnELl, Guillermo; Schmitter, Philippe C. \& Whitehead, Laurence (comps.): Transiciones desde un Gobierno Autoritario. América Latina. Buenos Aires, Barcelona y México: Paidós. Págs.147-185.

- (1989): The Chilean Political Process. London, Sydney and Wellington: Unwin Hyman, Thematic Studies in Latin America.

Garretón, Manuel A. (1991): "The Political Opposition and the Party System under the Military Regime", in Paul W. \& JAKSIC, Iván (eds.): The Struggle for Democracy in Chile, 1982-1990. Lincoln and London: University of Nebraska Press. Pages. 211-250.

Gaspar TAPIA, Gabriel (1988): "Chile: La Ofensiva Política de la Dictadura”. Estudios Sociológicos, vol.6, no.16, Enero-Abril. Págs. 179-203.

Gunther, Richard (1980): Public Policy in a No-Party State Spanish Planning and Budgeting in the Twilight of the Franquist Era. Berkeley, Los Angeles and London: University of California Press.
HABERMAS, Jurgen (1973): Legitimation Crisis. Translated by Thomas MacCartby. Legitimationoprobleme im Spatkapitalismus. Boston: Beacon Press.

HaGgard, Stephan (1990): “Authoritarianism and Democracy: Political Institutions and Economic Growth Revisited". Pathways from the Periphery. The Politics of Growth in the Newly Industrializing Countries. Ithaca and London: Cornell University Press. Pages 254-270.

HidAlgo, Paulo (1992): "La Transición a la Democracia: Aspectos Teóricos y Análisis de la Situación Chilena”. Revista del Centro de Estudios Constitucionales, 11, enero-abril.

Higley, John \& GunTHER, Richard (eds.) (1992): Elites and Democratic Consolidation. Latin America and Southern Europe. Cambridge: Cambridge University Press.

Hipsher, Patricia L. (1996): “Democratization and the decline of urban social movements in Chile and Spain". Comparative Politics, vol.28, n 3, April. Pages 273-97.

Horowitz, Irving L. (1975 [1964]): Los Anarquistas, I (La Teoria). Selección e introducción de I.L. Horowitz. Traducción: VV.AA. Madrid: Alianza Editorial.

Hunneus, Carlos (1985): "La Política de la Apertura y sus Implicancias para la Inauguración de la Democracia en Chile”. Revista de Ciencia Politica, vol. 7. Págs. 25-84.

Huntington, Samuel P. (1991): The Third Wave. Democratization in the Late Twentieth Century. Norman and London: University of Oklahoma Press.

KARL, Terry Lynn (1990): "Dilemmas of Democratization in Latin America”. Comparative Politics, vol. 23, $\mathrm{n}^{\circ} 1$, October. Pages 1-21.

KaUfman, Robert R. \& Stallings, Barbara (1991): “The Political Economy of Latm American Populism”, in DORNBUSCH, Rudiger \& EDWARDS, Sebastian: The Macroeconomics of Populism in Latin America. Chicago and London: University of Chicago Press. Pages 15-43.

KaUfman, Robert R. (1979): "Industrial Changes and Authoritarian Rule in Latin America: A Concrete Review of the Bureaucratic-Authoritarian Model", in Collier, David (ed.): The New Authoritariansm in Latin America. Princeton, N. J.: Princeton University Press. Pages 165-253.

Klarén, Peter F. \& Bossert, Thomas J. (1986): Promise of Development. Theories of Change in Latin America. Boulder and London: Westview Press.

LARrain B., Felipe (1991): “The Economic Challenges of Democratic Development”, in DRAKE, Paul W. \& JAKSIC, Iván (eds.): The Struggle for Democracy in Chile, 1982-1990. Lincoln and London: University of Nebraska Press. Pages 276-301.

LECHNER, Norbert (1986): La Conflictiva y Nunca Acabada Construcción del Orden Deseado. Madrid: Centro de Investigaciones Sociológicas, Colección: Monografías, 91. 
LinZ, Juan J. \& STEPAN, Alfred (1990): "Democratic Transition and Consolidation in Southem Europe. (With Reflections on Latin America and Eastern Europe)". Draft of paper to be delivered at the Conference on "Problems of Democratic Consolidation: Spain and the New Southern Europe", Madrid, July 6-8.

LinZ, Juan J. (1985): "From Primordialism to Nationalism", in TIRYAKIAN, Edward A. \& ROGwSKI, Ronald (eds.): New Nationalims of the Developed West. Boston: Allen \& Unwin. Pages 203-253.

- (1992): "La Transición a la Democracia en España en Perspectiva Comparada", en CotARelo, Ramón (comp.): Transición Politica y Consolidación Democrática. España (1975-1986). Madrid: C.I.S. Págs. 431-457.

LIPSET, Seymour M. (1969 [1959]): "Some Social Requisites of Democracy: Economic Development and Political Legitimacy", in CNUdDE, Charles F. \& Neubauer, Deane E. (eds.): Empirical Democratic Theory. Chicago: Markham Publishing Company. Pages 151-192.

MAINWARING, Scott \& SHARE, Donald (1986): "Transitions through Transaction: Democratization in Brazil and Spain", in SELCHER, Wayne (comp.): Political Liberalization in Brazil. Boulder, Co.: Westview. Pages 175-215.

Maravall, José M. (1985): La Politica de la Transición. Reimpresión de la 2a ed. (1984; $1^{a}$ ed.: 1982), Madrid: Taurus.

- (1993): "Las nuevas democracias. Economía y política”. Claves, 34. Julio-Agosto. Págs.13-23.

- (1995): Los resultados de la democracia. Un estudio del Sur y el Este de Europa. Madrid: Alianza Editorial, Alianza Universidad.

MuÑoz, Óscar (1977): Industrialización y Grupos de Interés. Santiago: CIEPLAN.

Nelson, Joan M. (ed.) (1990): Economic Crisis and Policy Change. Princeton, N. J.: Princeton University Press.

O'Donnell, Guillermo \& SCHMitter, Philippe C. (1986): Transitions from Authoritarian Rule. Tentative Conclusions about Uncertain Democracies. Foreward by Abraham F. Lowenthal. Baltimore and London: The Johns Hopkins University Press.

O'Donnell, Guillermo (1973): Modernization and Bureaucratic-Authoritarianismo: Studies in South American Politics. Berkeley: Institute of International Studies, University of California, Politics of Modernization Series, 9.

- (1979): "Tensions in the Bureaucratic-Authoritarian State and the Ouestion of Democracy", in Collier, David (ed.): The New Authoritarianism in Latin America. Princeton, N. J.: Princeton University Press. Pages 285-318.

- (1988): "Introducción a los Casos Latinoamericanos", in O'Donnell, G., Schmitter, Philippe C. \&
Whitehad, Lawrence (comps.): Transiciones desde un Gobierno Autoritario. América Latina. Translated by Jorge Piatigorsky. Transitions from Authoritarian Rule. Latin America. Buenos Aires, Barcelona, México: Paidós. Pages 15-36.

OfFE, Claus \& RONGE, Volker (1982): "Theses on the Theory of the State", in Giddens, Anthony \& Held, David: Classes, Power, and Conflict. Classical and Contemporany Debates. Berkeley and Los Angeles: University of California Press. Pages 249-256.

OfFe, Claus (1984): Contradictions of the Welfare State. Cambridge, Mass.: The M.I.T. Press.

OrREgo Vicuña, Francisco (1985): "Consenso y Disenso en la Transición a la Democracia: el Caso de Chile”, en idem (comp.): Transición a la Democracia en América Latina. Buenos Aires: Grupo Editor Latinoamericano, Colección: Estudios Políticos y Sociales.

PrewitT, Kenneth \& STONE, Alan (1973): The Ruling Elite: Elite Theory, Power and American Democracy. New York: Harper \& Row.

PRZEWORSKI, Adam (1991): Democracy and the Market. Cambridge: Cambridge University Press, Studies in Rationality and Social Change.

- (1992): "The Games of Transitions" in MAINWARING, Scott; O'Donnell, Guillermo \& Valenzuela, J. Samuel (eds.): Issues in Democratic Consolidation: The New South American Democracies in Comparative Perspective. Notre Dame, Indiana: University of Notre Dame Press. Pages 105-152.

Putnam, Robert D. (1976): The Comparative Study of Political Elites. Englewood Cliffs, N. J.: Prentice-Hall.

RojAs HERnÁndeZ, Jorge (1993): "El Movimiento Sindical Chileno en la Transición a la Democracia". Proposiciones, 22, págs. 54-79.

Ruiz-TAGLE, Jaime (1985): El Sindicalismo Chileno después del Plan Laboral. Santiago: PET.

- (1989): "Trade Unionism and the State under the Chilean Military Regime", in EpsteIn, Edward C. (ed.): Labor Autonomy and the State in Latin America. London, Sydney, Wellington: Unwin Hyman. Pages 73-100.

Rustow, Dankwart A. (1970): "Transitions to Democracy. Toward a Dynamic Model". Comparative Politics, vol. 2, n 3, April. Pages 337-363.

SARTORI, Giovani (1987): The Theory of Democracy Revisited. The Contemporary Dabate. Clatham, N. J.: Clatham House Publishers.

SERRA, José (1979): “Three Mistaken Theses Regarding the Connection between Industrialization and Authoritarian Regimes", in Collier, David: The New Authoritarianism in Latin America. Princeton, N. J.: Prmceton University Press. Pages 99-163.

SHEAHAN, John (1980): "Market-Oriented Economic Policies and Political Repression in Latin America". 
Economic Development and Cultural Change, vol. 28, $n^{\circ} 2$, January 1980. Pages 267-291.

SILVA, Eduardo (1991): “The Political Economy of Chile's Regime Transition: From Radical to Pragmatic NeoLiberal Policies", in DRAKE, Paul W. E JAKSIC, Iván (eds.): The Struggle for Democracy in Chile, 1982-1990. Lincoln and London: University of Nebraska Press. Pages 98-127.

- (1996): "From dictatorship to democracy: The business-state nexus in Chile's economic transformation, 1975-1994". Comparative Politics, vol. 28, n³ 3, April. Pages 299-320.

TARROW, Sidney (1994): Power in movement. Social movements, collective action and politics. Cambridge: Cambridge University Press, Cambridge Studies in Comparative Politics.

- (1995): "Mass mobilization and regime change: Pacts, reform, and popular power m Italy (1918-1922) and Spain (1975-1978)", in GUNTHER, Richard; Diamandouros, Nikiforos, and PuHLE, Hans-Jurgen: The Politics of Consolidation. Southern Europe in Comparative Perspective. Baltimore: The Johns Hopkins University Press. Pages 204-30.
Valenzuela, Arturo \& Valenzuela, J. Samuel (1982): "Partidos de Oposición bajo el Régimen Autoritario Chileno". Revista Mexicana de Sociología, vol. 44, n² 2 págs.599-648.

Valenzuela, J. Samuel (1974): "The Chilean Labor Movement: The Industrialization of Conflict". Human Factor, vol. 12, n 2-3. Pages 31-65.

- (1989): "Labor Movements in Transitions to Democracy. A Framework for Analysis". Comparative Politics, vol. 21, nº 4, July. Pages 445-472.

VARAS, Augusto (1991): "The Crisis of Legitimacy of Military Rule in the 1980s", in DRAKE, Paul W. \& JAKSIC, Iván (eds.): The Struggle for Democracy in Chile, 1982-1990. Lincoln and London: University of Nebraska Press. Pages 73-97.

Vergara, Pilar (1990): "Políticas hacia la Extrema Pobreza, 1973-1988”. FLACSO.

- (1993): "Ruptura y Continuidad en la Política Social del Gobierno Democrático". Estudios Sociales, 44, abril, FLACSO.

- (1994): "Las políticas sociales en Chile". Revista Mexicana de Sociología, año LVI, $\mathrm{n}^{\circ} 3$, julio-septiembre. págs .205-30.

\section{RESUMEN}

Según las propias palabras del autor, el presente artículo intenta analizar la importancia del nivel y la naturaleza de las movilizaciones sociales de presión y/o protesta en la determinación tanto del acaecimiento como de la naturaleza del proceso de transición hacia la democracia en Chile en los últimos años. Este análisis se presenta como un estudio complementario (aunque crítico) del modelo explicativo de los especialistas en transitología de la contingencia. Desde esta perspectiva, el autor sugiere que dado que la desmovilización social comenzó en el período de liberalización del régimen (1985/86) el costo de la misma fue mucho menor para las autoridades dictatoriales.

\section{ABSTRACT}

This article analyses the characteristics of social protest mobilizations and their implications on the transition towards democracy in Chile. This analysis criticizes and complements those explanations of democratic transitions which emphasize contingence. In this analysis, the author argues that since social mobilization started in the same period as the liberalization process (1985-86), such a mobilization had low costs for the military regime. 